\title{
Pachymic acid inhibits growth and induces cell cycle arrest and apoptosis in gastric cancer SGC-7901 cells
}

\author{
KUAN-XUE SUN ${ }^{1,2}$ and HONG-WEI XIA ${ }^{2}$ \\ Departments of ${ }^{1}$ General Surgery and ${ }^{2}$ Ultrasound, Gong Li Hospital of Shanghai Pu Dong New District, \\ Shanghai 200135, P.R. China
}

Received April 29, 2016; Accepted December 19, 2017

DOI: $10.3892 / 01.2018 .8899$

\begin{abstract}
The aim of the present study was to elucidate the anticancer effect of pachymic acid (PA) in gastric cancer SGC-7901 cells and the potential molecular mechanisms involved. Cell Count kit-8 assay was performed to examine the effect of PA on the cell proliferation of SGC-7901 cells. Cell cycle, cell apoptosis, mitochondria membrane potential (D $\psi \mathrm{m})$ and reactive oxygen species (ROS) analysis were assessed by flow cytometry, respectively. DNA fragmentation assay was performed by Hoechst 33258 staining. Western blotting was performed to detect the effect of various concentrations of PA on the levels of BCL2 associated X protein (Bax) expression as well as B-cell lymphoma 2 (Bcl-2), cytochrome C (cyt-c) and caspase-3 in SGC-7901 cells. It was demonstrated that PA was able to significantly inhibit the viability and induce $G_{0} / G_{1}$ cell cycle arrest of SGC-7901 cells in a concentration-dependent manner. The apoptotic rate and ROS generation were markedly increased, while D $\psi \mathrm{m}$ was decreased following the treatment of SGC-7901 cells with various concentrations of PA. Moreover, the expression of Bax, cytochrome c and caspase-3 were markedly increased and Janus kinase 2 (JAK2)/signal transducer and activator of transcription 3 (STAT3) was significantly inactivated and BCL-2 expression was decreased following PA treatment in SGC-7901 cells. Notably, JAK2 inhibitor (AG490) mimics the effects of PA on the viability and apoptosis of SGC-7901 cells. Further in vivo study indicated that treatment with PA significantly inhibited the growth of tumor in nude mice that were transplanted with SGC-7901 cells in a concentration-dependent manner. These results may advance the current understanding of the anticancer mechanisms of PA in gastric cancer.
\end{abstract}

Correspondence to: Dr Hong-Wei Xia, Department of Ultrasound, Gong Li Hospital of Shanghai Pu Dong New District, 219 Miao Pu Road, Pu Dong, Shanghai 200135, P.R. China

E-mail: hongweixiax@126.com

Key words: pachymic acid, gastric cancer, mitochondrial pathway, apoptosis, Janus kinase 2/signal transducer and activator of transcription 3

\section{Introduction}

Gastric cancer is a highly invasive and aggressive malignancy that ranks the fourth most common cancer and the leading cause of cancer-associated mortality in China $(1,2)$. The incidence of gastric cancer is approximately two times higher in men compared with women. Studies have shown that individuals infected with Helicobacter pylori have an increased risk of gastric cancer $(3,4)$ and a poor prognosis in most countries, with a 5-year relative survival rate $<30 \%$ (5).

The advancement of modern medicine and technology has been accompanied with a series of intensive studies on cancer tumorigenesis. The application of naturally occurring compounds with anticancer properties can be regulated by a variety of mechanisms, including crosslinking of DNA strands and immune responses, induction of cell cycle arrest, which consequently lead to cell death (6,7). A number of studies indicated that cancer cell apoptosis could be considered a point of convergence for all anticancer therapies, and active phytochemicals have a direct role in promoting apoptosis $(8,9)$.

Pachymic acid (PA) is a lanostane-type triterpenoid from Poriacocos, which is an important component in traditional Chinese medicine. Previous studies have shown that PA possesses anti-emetic, anti-inflammatory and anticancer properties. It has been demonstrated that PA is able to inhibit the proliferation and invasion of pancreatic cancer cells by decreasing MMP-7 expression(10). PA was able to activate reactive oxygen species (ROS)-dependent JUN N-terminal kinase mitochondrial and endoplasmic reticulum stress pathways following cell cycle arrest at G2/M phase and cell apoptosis occurred in lung cancer cells (11). PA reduced proliferation and induced apoptosis through inactivation of AKT signaling and downregulation of AKT downstream protein expression in prostate cancer cells (12). Another study demonstrated that PA is able to stimulate glucose uptake by enhancing the expression and translocation of glucose transporter type 4 (13). However, the therapeutic effects and potential mechanisms of PA on gastric cancer are poorly understood and therefore remain to be evaluated.

The present study aimed to examine the hypothesis that PA is able to have an effect on the viability, cell cycle progression and apoptosis of SGC-7901 human gastric cancer cells in vitro. Herein, the effects of PA on DNA synthesis, mitochondrial function and ROS production, as well as the 
expression levels of Bax (BCL2 associated X protein)/B-cell lymphoma 2 (Bcl-2) ratio, cytochrome c (cyt-c) and caspase-3 and the activation of Janus kinase 2 (JAK2)/signal transducer and activator of transcription 3 (STAT3) in SGC-7901 were also investigated.

\section{Materials and methods}

Materials. PA was purchased from Nanjing Zelang Medical Technological Co. Ltd., (Nanjing, China) and dissolved in dimethyl sulfoxide (DMSO) at $10 \mathrm{mg} / \mathrm{ml}$ and stored at $-20^{\circ} \mathrm{C}$. Annexin V-fluorescein isothiocyanate (FITC)/propidium iodide (PI) apoptosis detection kit was supplied by Biouniquer Technology Co. Ltd. (Nanjing, Jiangsu, China). Hoechst 33258 was purchased from Beyotime Institute of Biotechnology (Shanghai, China). Tetramethylrhodamine, methyl ester (TMRM) was purchased from Santa Cruz Biotechnology, Inc., (Dallas, TX, USA). The fluorescent probe dihydroethidium (DHE) was purchased from Vigorous Biotechnology Beijing Co., Ltd (Beijing, China).

Cell culture. The SGC-7901 human gastric cancer cell line was obtained from American Type Culture Collection, (Manassas, VA, USA). SGC-7901 cells were cultured in DMEM medium (Thermo Fisher Scientific, Inc., Waltham, MA, USA) containing $10 \%$ fetal bovine serum (FBS; Gibco; Thermo Fisher Scientific, Inc.), $100 \mathrm{U} / \mathrm{ml}$ penicillin $\mathrm{G}$ and $100 \mu \mathrm{g} / \mathrm{ml}$ streptomycin in a humidified incubator at $37^{\circ} \mathrm{C}$ and $5 \% \mathrm{CO}_{2}$.

Cell proliferationassay. The Cell Count kit-8(CCK-8; Signalway Antibody LLC, College Park, MD, USA) was performed to examine the effects of PA and AG490 (Selleck Chemicals, Houston, TX, USA) on cell proliferation. Briefly, SGC-7901 cells were cultured in 96-well plates to $80 \%$ confluence. Different concentrations of PA $(20,40$ and $80 \mu \mathrm{M})$ and AG490 $(100 \mu \mathrm{M})$ were added into each well at $12,24,48$ and $72 \mathrm{~h}$, and then incubated with CCK- 8 solution at $37^{\circ} \mathrm{C}$ as the manufacturer's instructions followed by further $1 \mathrm{~h}$ incubation under the same incubator conditions. The absorbance was read for the supernatant of each well at $450 \mathrm{~nm}$ using a microplate reader (Utrao Medical Instrument Co. Ltd., Shanghai, China).

Flow cytometric analysis of cell cycle. SGC-7901 cells $\left(3 \times 10^{5}\right.$ cells/well) were dispensed into 6-well plates and treated with different concentrations of PA (20, 40 and $80 \mu \mathrm{M})$ for $24 \mathrm{~h}$. The cells were harvested and fixed in 70\% ethanol and then stored at $-20^{\circ} \mathrm{C}$ for $24 \mathrm{~h}$. The cells were washed twice with PBS and resuspended in $100 \mu \mathrm{l}$ RNase $\mathrm{A}$ at $37^{\circ} \mathrm{C}$, followed by staining with $50 \mu \mathrm{g} / \mathrm{ml}$ propidium iodide (PI) for $10 \mathrm{~min}$ at room temperature in the dark. The stained cells were analyzed using a flow cytometer (BD Biosciences, Franklin Lakes, NJ, USA). The DNA content at $\mathrm{G}_{0} / \mathrm{G}_{1}, \mathrm{~S}$ and $\mathrm{G} 2 / \mathrm{M}$ was analyzed using BD Accuri C6 software (version, 1.0.264.21; BD Biosciences).

Flow cytometric analysis of apoptosis. SGC-7901 cells $\left(3 \times 10^{5}\right.$ cells/well) were dispensed into 6-well plates and treated with different concentrations of PA (20,40 and $80 \mu \mathrm{M})$ and AG490 $(100 \mu \mathrm{M})$ for $24 \mathrm{~h}$. Double staining with Annexin V fluorescein isothiocyanate (FITC)/PI was performed following the manufacturer's protocol. A total of $5 \times 10^{4}$ SGC-7901 cells were collected by centrifugation at $1,000 \mathrm{x}$ g for $5 \mathrm{~min}$ at $25^{\circ} \mathrm{C}$ and then resuspended in a binding buffer containing $195 \mu \mathrm{l}$ Annexin V FITC and $5 \mu \mathrm{l}$ PI for $10 \mathrm{~min}$ in an ice bath in the dark prior to flow cytometric analysis.

DNA fragmentation assay. SGC-7901 cells were dispensed into 6-well plates and treated with a series of concentrations of PA $(20,40$ and $80 \mu \mathrm{M})$ for $24 \mathrm{~h}$. Then, the cells were harvested and fixed with $3 \%$ paraformaldehyde for $5 \mathrm{~min}$ at room temperature. After dying, the cells were stained with Hoechst $33258(10 \mathrm{ml})$ for $10 \mathrm{~min}$, following mounting with $20 \mathrm{mM}$ citric acid and $50 \mathrm{mM}$ orthophosphate in $50 \%$ glycerol. The cells were then stored at $-20^{\circ} \mathrm{C}$ prior to analysis. Following treatment, the cells were washed with PBS, and features of apoptosis (including condensed and fragmented nuclei) were evaluated using a fluorescence microscope (DMI3000B; Leica Microsystems GmbH, Wetzlar, Germany).

Flow cytometric analysis of D $\psi \mathrm{m}$ and ROS generation. SGC-7901 cells $\left(3 \times 10^{5}\right.$ cells/well) were dispensed into 6-well plates and treated with different concentrations of PA (20, 40 and $80 \mu \mathrm{M}$ ) for $24 \mathrm{~h}$ at $37^{\circ} \mathrm{C}$. D $\psi \mathrm{m}$ was detected using TMRM. A total of $1 \times 10^{6} / \mathrm{ml} \mathrm{SGC-7901} \mathrm{cells} \mathrm{were} \mathrm{resuspended} \mathrm{with}$ $100 \mathrm{nM}$ TMRM, and the cells were incubated in the dark at $37^{\circ} \mathrm{C}$ for $15-20 \mathrm{~min}$ and analyzed using a flow cytometer. The intracellular levels of ROS were assessed using the fluorescent probe DHE. The SGC-7901 cells $\left(1 \times 10^{6} / \mathrm{ml}\right)$ were resuspended with $50 \mu \mathrm{M} \mathrm{DHE}$ at $37^{\circ} \mathrm{C}$ for $30 \mathrm{~min}$, and the intensity of fluorescence was measured using a flow cytometer.

Western blot analysis. The cells $\left(1 \times 10^{6}\right.$ cell/well $)$ were dispensed into 6-well plates followed by treatment with PA and AG490 for the indicated times and lysed using radioimmunoprecipitation buffer containing protease inhibitor Beyotime Institute of Biotechnology, Inc.). The protein concentration was quantified using a bicinchoninic acid protein assay kit (Thermo Fisher Scientific, Inc.). The proteins $(30 \mu \mathrm{g})$ were separated by $10 \%$ SDS-PAGE and further transferred onto a nitrocellulose membrane (EMD Millipore, Billerica, MA, USA). Following blocking with $5 \%$ non-fat milk overnight at $4^{\circ} \mathrm{C}$, the membranes were probed with specific primary antibodies: Polyclonal rabbit anti-Bax (1:1,000; cat. no. sc493; Santa Cruz Biotechnology, Inc.), polyclonal rabbit anti-Bcl-2 (1:1,000; cat. no. sc-492; Santa Cruz Biotechnology, Inc.), polyclonal mouse anti-cyt-c (1:1,000; cat. no. ab13575; Abcam, Cambridge, MA, USA) and monoclonal rabbit anti-caspase-3 (1:500; cat. no. ab44976; Abcam) overnight at $4^{\circ} \mathrm{C}$. GAPDH was used for the normalization of each protein to ensure the loading of equal quantities of protein. After washing three times with TBST for $15 \mathrm{~min}$, the blots were incubated with goat anti-rabbit or goat anti-mouse horseradish peroxidase-conjugated secondary antibodies (1:1,000; cat. no. A0208 and A0216; Beyotime Institute of Biotechnology) in TBST for $1 \mathrm{~h}$ at room temperature. Following another round of washing, the signals were detected by enhanced chemiluminescence method (Pierce; Thermo Fisher Scientific, Inc.) and quantified by densitometry (Bio-Rad Laboratories, Inc., Hercules, CA, USA).

Tumor xenograft model. In order to clarify the role of PA in vivo, 5 -week-old male athymic nude mice $(\mathrm{n}=24)$ were used 
A

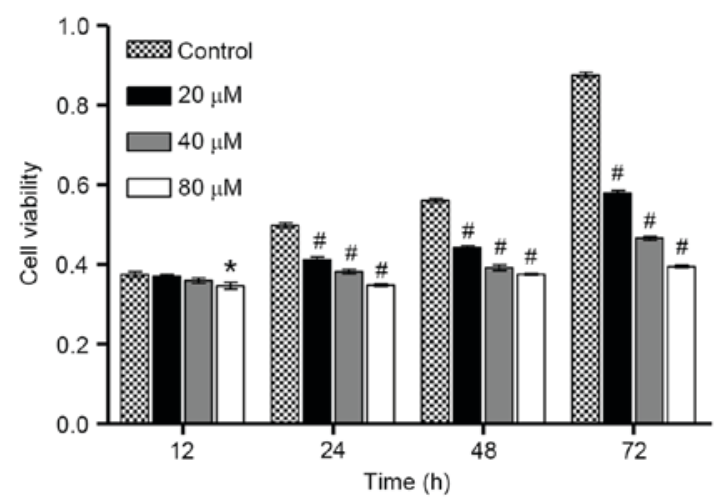

B

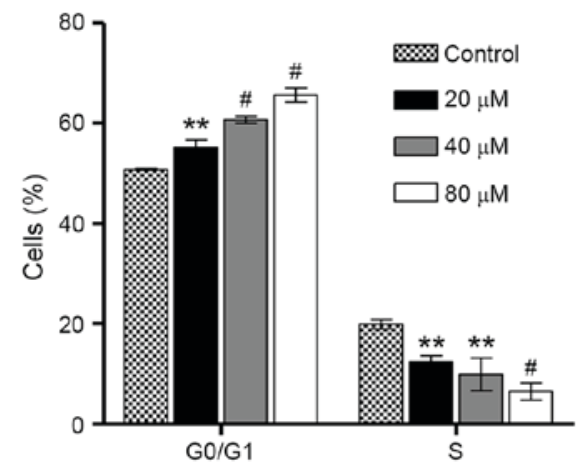

C 20 40
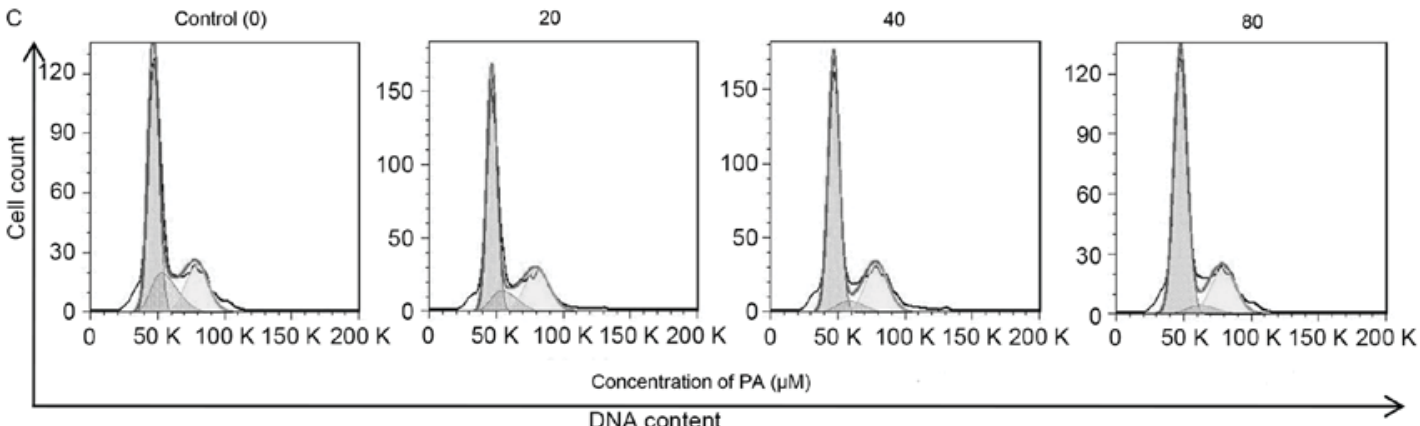

DNA content

Figure 1. Effect of pachymic acid on the growth and cell cycle of SGC-7901 gastric cancer cells. (A) SGC-7901 cells were treated with different concentrations of PA $(20,40$ and $80 \mu \mathrm{M})$ for 12, 24, 48 and $72 \mathrm{~h}$, and CCK-8 assay was performed to examine cell viability. (B) SGC-7901 cells were treated with different concentrations of PA $(20,40$ and $80 \mu \mathrm{M})$ for $24 \mathrm{~h}$, and cell population in $\mathrm{G}_{0} / \mathrm{G}_{1}$ and $\mathrm{S}$ phase was assessed by flow cytometric analysis. (C) Representative cell cycle profiles of SGC-7901 cells after PA treatment. ${ }^{*} \mathrm{P}<0.05,{ }^{* *} \mathrm{P}<0.01,{ }^{*} \mathrm{P}<0.001$ vs. the control group.
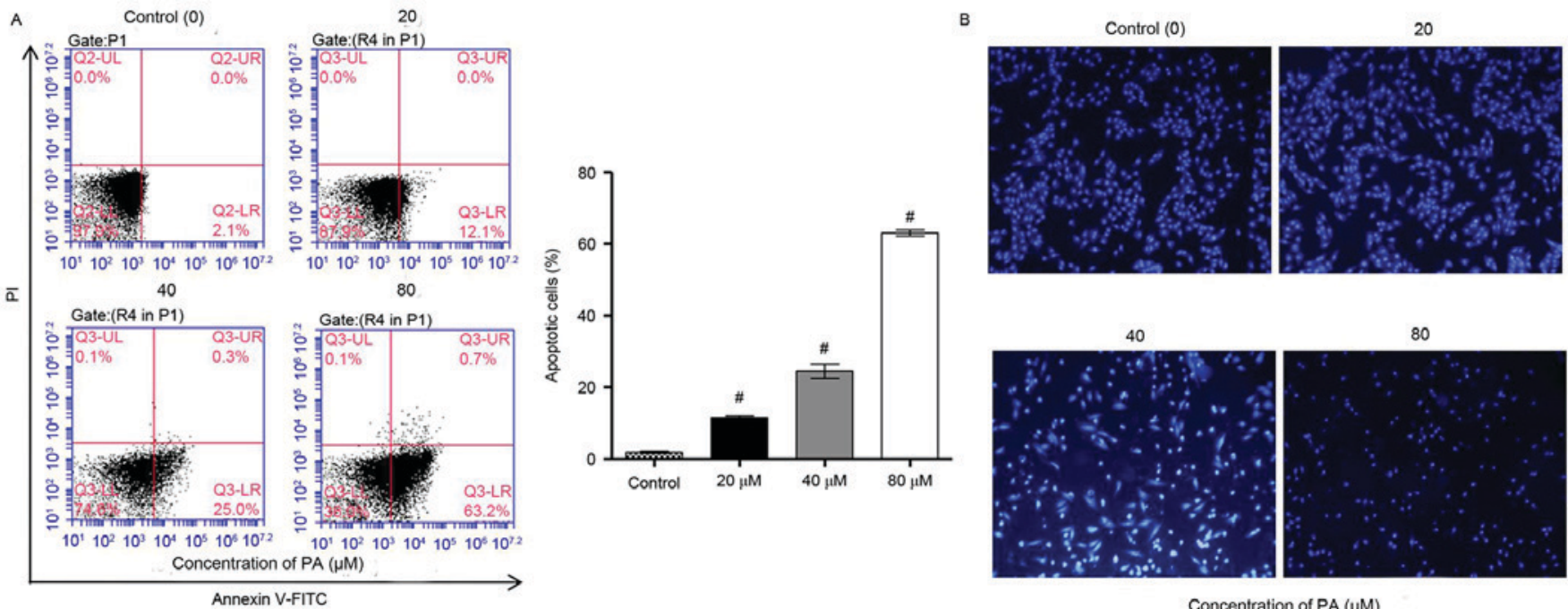

Concentration of $\mathrm{PA}(\mu \mathrm{M})$

Figure 2. Effect of PA on the apoptosis of SGC-7901 gastric cancer cells. SGC-7901 cells were treated with different concentrations of PA (20, 40 and $80 \mu \mathrm{M}$ ) for $24 \mathrm{~h}$. (A) Annexin V-FITC/PI staining and (B) Hoechst 33258 fluorescence staining were used to detect cell apoptosis. Magnification, $\mathrm{x} 200$. ${ }^{\#} \mathrm{P}<0.001$ vs. the control group. PA, pachymic acid.

in the present study. A total of $2 \times 10^{6}$ SGC-7901 cells were injected subcutaneously into the left armpit of these nude mice to establish the gastric cancer xenograft model. A total of 24 male athymic nude mice were randomly assigned to four different groups with six mice per group: Vehicle control (0.1\% DMSO in physiological saline) and PA (10, 30 and $60 \mathrm{mg} / \mathrm{kg}$ ). Following 1-2 weeks of tumor formation, the tumor size was determined every 4 days as previously described (14). The mice were sacrificed, and the tumors were weighed on a digital balance following intraperitoneal injection of PA every day for 4 weeks. All the experiments were approved by the Animal Ethics Committee at Gongli Hospital of Shanghai Pu Dong New District (Shanghai, China).

Statistical analysis. The data was presented as the mean \pm standard deviation, and significant differences between two groups were analyzed with the unpaired, two-tailed Student t-test. One-way analysis of variance, followed by 

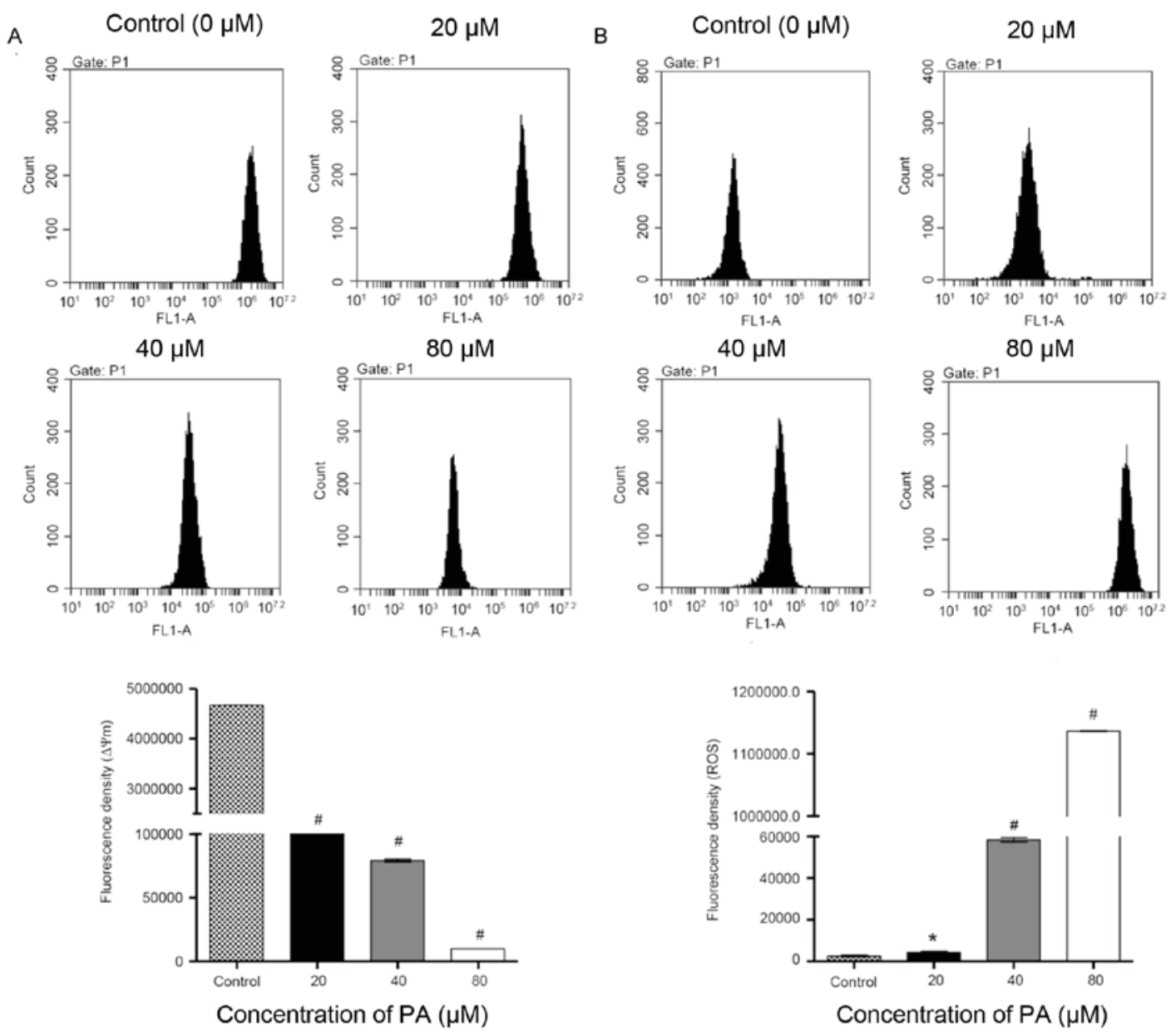

Figure 3. Effect of PA on $\Delta \psi \mathrm{m}$ and ROS generation in SGC-7901 gastric cancer cells. SGC-7901 cells were treated with different concentrations of PA (20, 40 and $80 \mu \mathrm{M}$ ) for $24 \mathrm{~h}$, and the $\Delta \psi \mathrm{m}$ was determined by (A) tetramethylrhodamine staining and analyzed by flow cytometry, and (B) ROS generation was determined by dihydroethidium staining and analyzed by flow cytometry. ${ }^{~} \mathrm{P}<0.001$ and ${ }^{*} \mathrm{P}<0.05$ vs. the control group. PA, pachymic acid; ROS, reactive oxygen species.

Tukey's post hoc test, was used to analyze the significance of differences between more than two groups. Statistical analyses were performed using GraphPad Prism software (version 5.0; GraphPad Software, Inc., La Jolla, CA, USA). P $<0.05$ was considered to indicate a statistically significant difference.

\section{Results}

$P A$ inhibits the viability of SGC-7901 gastric cancer cells in vitro. To examine the biological function of $\mathrm{PA}$ in gastric cancer, CCK- 8 assay was performed to investigate the viability of SGC-7901 cells following exposure to different concentrations of PA $(0,20,40$ and $80 \mu \mathrm{M})$ for 12,24 , 48 and 72 h. As shown in Fig. 1A, PA induced significant decreases in the viability of SGC-7901 cells in a time- and concentration-dependent manner. To examine whether the inhibitory effect of PA on the viability of SGC-7901 cells was associated with the induction of cell cycle arrest, flow cytometry was performed on the SGC-7901 cells that were treated with different concentrations of PA $(0,20,40$ and $80 \mu \mathrm{M})$ for $24 \mathrm{~h}$. As shown in Fig. $1 B$ and $C$, the cell population in $G_{0} / G_{1}$ phase of SGC-7901 cells was significantly increased by PA treatment in a concentration-dependent manner, accompanied with a decrease in the cell population in S phase, suggesting that PA is able to induce cell cycle arrest at $\mathrm{G}_{0} / \mathrm{G}_{1}$ phase. However, PA treatment did not affect the cell population at $\mathrm{G} 2 / \mathrm{M}$ phase of SGC-7901 cells. These observations indicate that the inhibition of cell growth by PA is implicated with the induction of $\mathrm{G}_{0} / \mathrm{G}_{1}$ phase arrest.

$P A$ induces the apoptosis of SGC-7901 gastric cancer cells in vitro. It was further examined whether the inhibitory effect of PA on the viability of SGC-7901 cells was associated with induction of apoptosis. Flow cytometry using Annexin V-PI staining analysis were performed on the SGC-7901 cells that were treated with various concentrations of PA $(0,20,40$ and $80 \mu \mathrm{M})$ for $24 \mathrm{~h}$. The data indicated that PA treatment significantly increased the apoptosis of SGC-7901 cells in a concentration-dependent manner (Fig. 2A). Furthermore, the effects of PA on apoptosis were examined by Hoechst 33258 staining, which is able to differentiate between normal and apoptotic cells. Data from fluorescence microscopy indicated that PA treatment markedly increased the apoptosis of SGC-7901 cells in a concentration-dependent manner, where chromosome condensation and nuclear fragmentation were observed in PA-treated SGC-7901 cells (Fig. 2B). Taken together, these results indicated that the inhibition of cell growth and the 
A
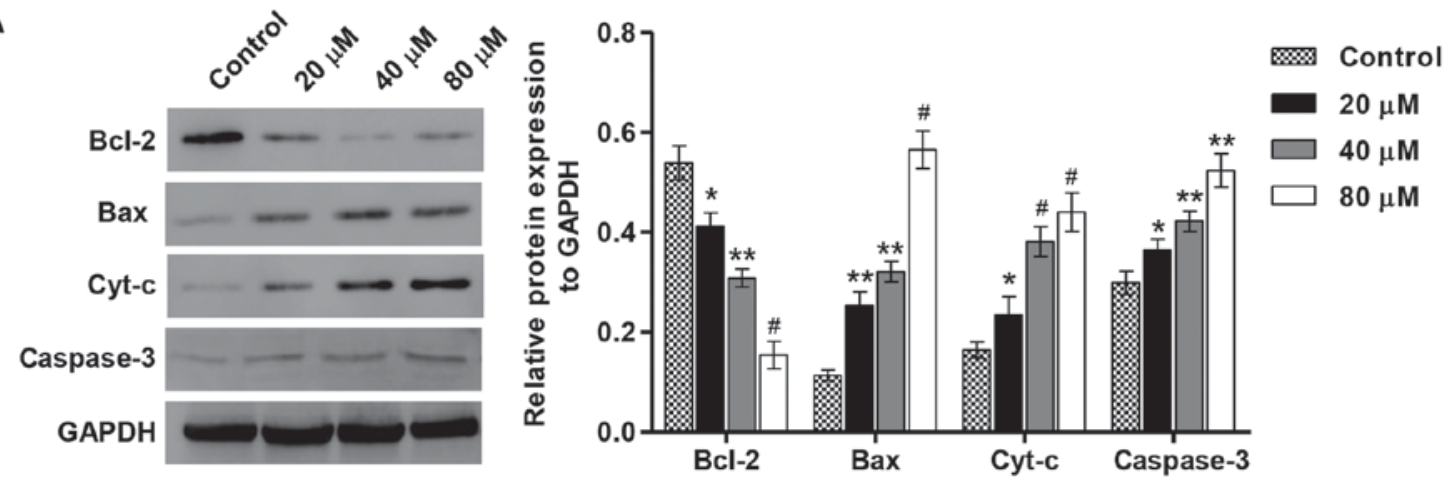

B
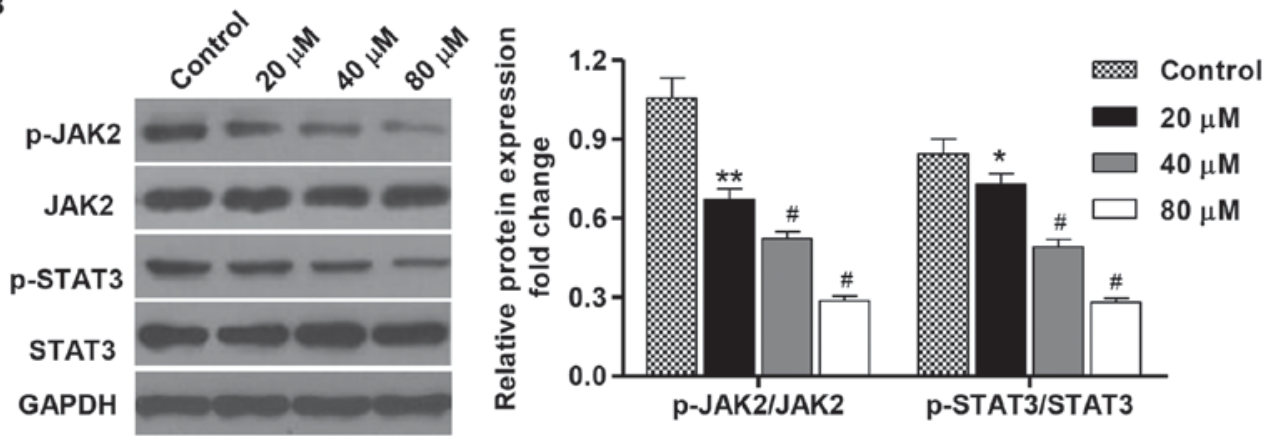

Figure 4. Effect of PA on protein expression and JAK2/STAT3 activation in SGC-7901 gastric cancer cells. SGC-7901 cells were treated with different concentrations of PA (20, 40 and $80 \mu \mathrm{M})$, and protein expression of (A) Bcl-2, Bax, cyt-c and caspase-3. (B) The activation of JAK2 and STAT3 was assessed by western blotting. These experiments were performed on the same membrane. ${ }^{*} \mathrm{P}<0.05,{ }^{* *} \mathrm{P}<0.01,{ }^{\prime \prime} \mathrm{P}<0.001$ vs. the control group. Bax, BCL2 associated $\mathrm{X}$ protein; Bcl-2, B-cell lymphoma 2; cyt-c, cytochrome c; JAK2, Janus kinase 2; p-, phosphorylated; STAT3, signal transducer and activator of transcription 3; PA, pachymic acid.

induction of cell cycle arrest by PA are implicated with the induction of apoptosis.

Effects of PA on mitochondrial membrane potential $(\Delta \psi m)$ and ROS generation. Mitochondria have an essential role in death signal transduction during the apoptotic process, where the mitochondrial membrane pores are opened and $\Delta \psi \mathrm{m}$ is disrupted (15). As presented in Fig. 3A, data from flow cytometry indicated that PA-treated SGC-7901 cells exhibited a significant decrease in $\Delta \psi \mathrm{m}$ in a concentration-dependent manner in comparison with the control cells. Previous studies have reported that ROS generation is able to trigger cell apoptosis by activating the mitochondrial pathway (16). Fluorescence probe DHE was therefore used in SGC-7901 cells that were treated with different concentrations of PA $(0,20,40$ and $80 \mu \mathrm{M})$ for $24 \mathrm{~h}$. As indicated in Fig. 3B, the treatment with PA significantly increased the intracellular accumulation of ROS in a concentration-dependent manner. Taken together, these data demonstrate that induction of cell apoptosis by PA is implicated with the mitochondrial pathway.

Effects of PA on protein expression and JAK2/STAT3 activation in SGC-7901 gastric cancer cells. To elucidate the mechanism of PA-induced apoptosis in SGC-7901 cells, the expression of apoptosis-associated proteins was detected by western blotting. As indicated in Fig. 4A, the treatment with PA $(20,40$ and $80 \mu \mathrm{M})$ for $48 \mathrm{~h}$ increased the levels of Bax, cyt-c and caspase-3proteins in a concentration-dependent manner in comparison with the control cells, but decreased the expression level of Bcl-2. Moreover, the inactivation of JAK2 and STAT3 was also detected in SGC-7901 cells that were treated with different concentrations of PA (Fig. 4B). Taken together, these data indicate that induction of cell apoptosis by PA is implicated with modulation of Bcl-2, Bax, cyt-c and caspase- 3 expression as well as the inactivation of JAK2/STAT3 signaling.

Inhibition of the JAK2/STAT3 signaling pathway inhibits cell viability and induces apoptosis in SGC-7901 gastric cancer cells. To confirm that the PA-induced tumor inhibitory effects are dependent on the downstream activation of JAK2/STAT3, the effects of a specific JAK2 inhibitor (AG490) on the viability and apoptosis of cells that were treated with AG490 $(100 \mu \mathrm{M})$ and in the absence or presence of PA $(80 \mu \mathrm{M})$ were determined. The treatment of SGC-7901 cells with AG490 $(100 \mu \mathrm{M})$ for $1 \mathrm{~h}$ resulted in the inhibition of JAK2 and STAT3 activation (Fig. 5A). Furthermore, the treatment with AG490 alone or in combination with PA significantly inhibited the viability and induced the apoptosis of SGC-7901 cell compared with the control (Fig. 5B-D). Consistent with these findings, AG490 treatment in SGC-7901 cells resulted in increases in the levels of Bax, cyt-c and caspase-3 proteins in comparison with the control cells, but the expression level of Bcl-2 was decreased (Fig. 5E). These data suggest that PA is able to inhibit cell viability and induce apoptosis via inactivation of the JAK2/STAT3 signaling pathway in SGC-7901 cells.

Antitumor activity of PA in vivo. In order to elucidate the antitumor activity of PA in vivo, tumor xenograft models 

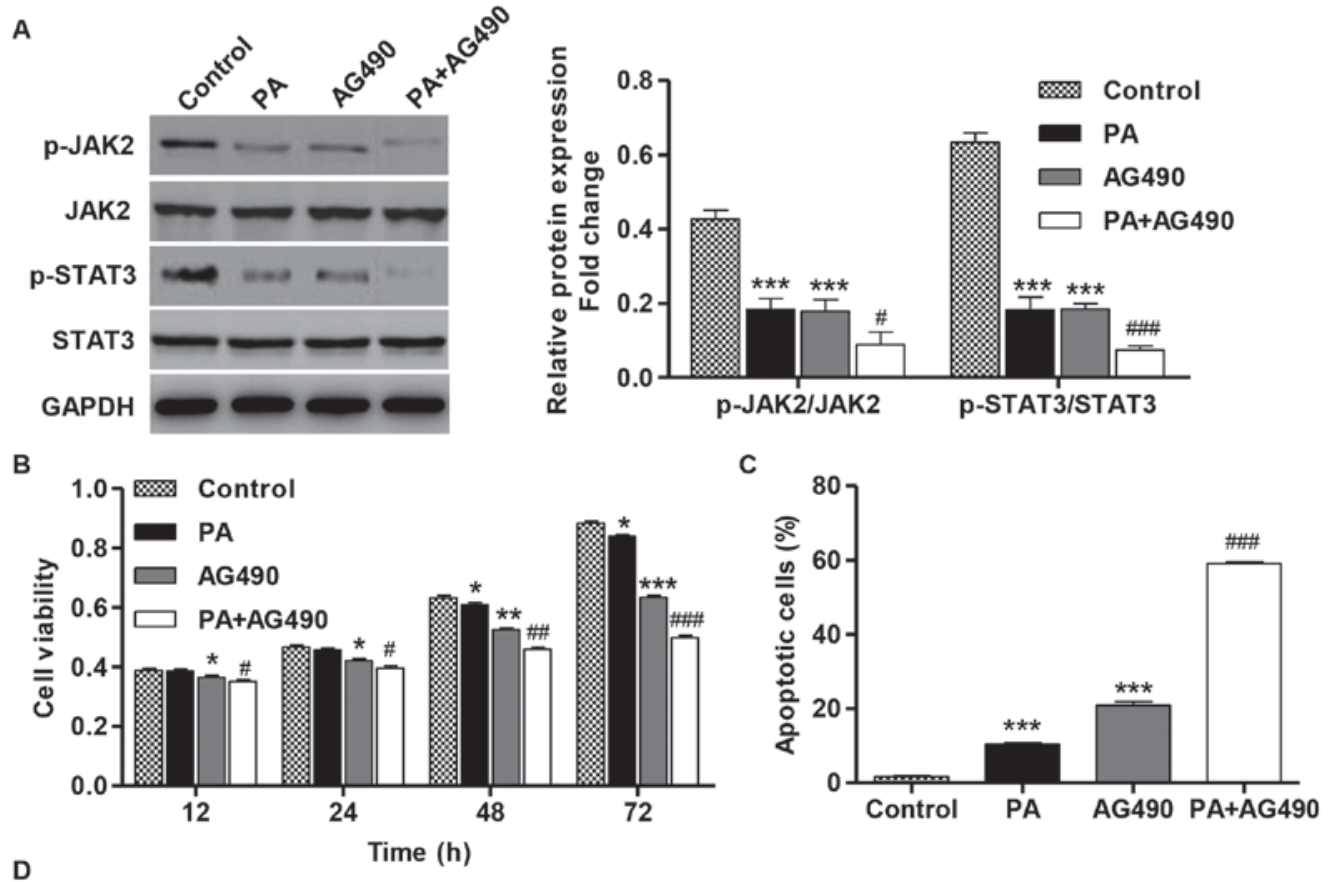

D
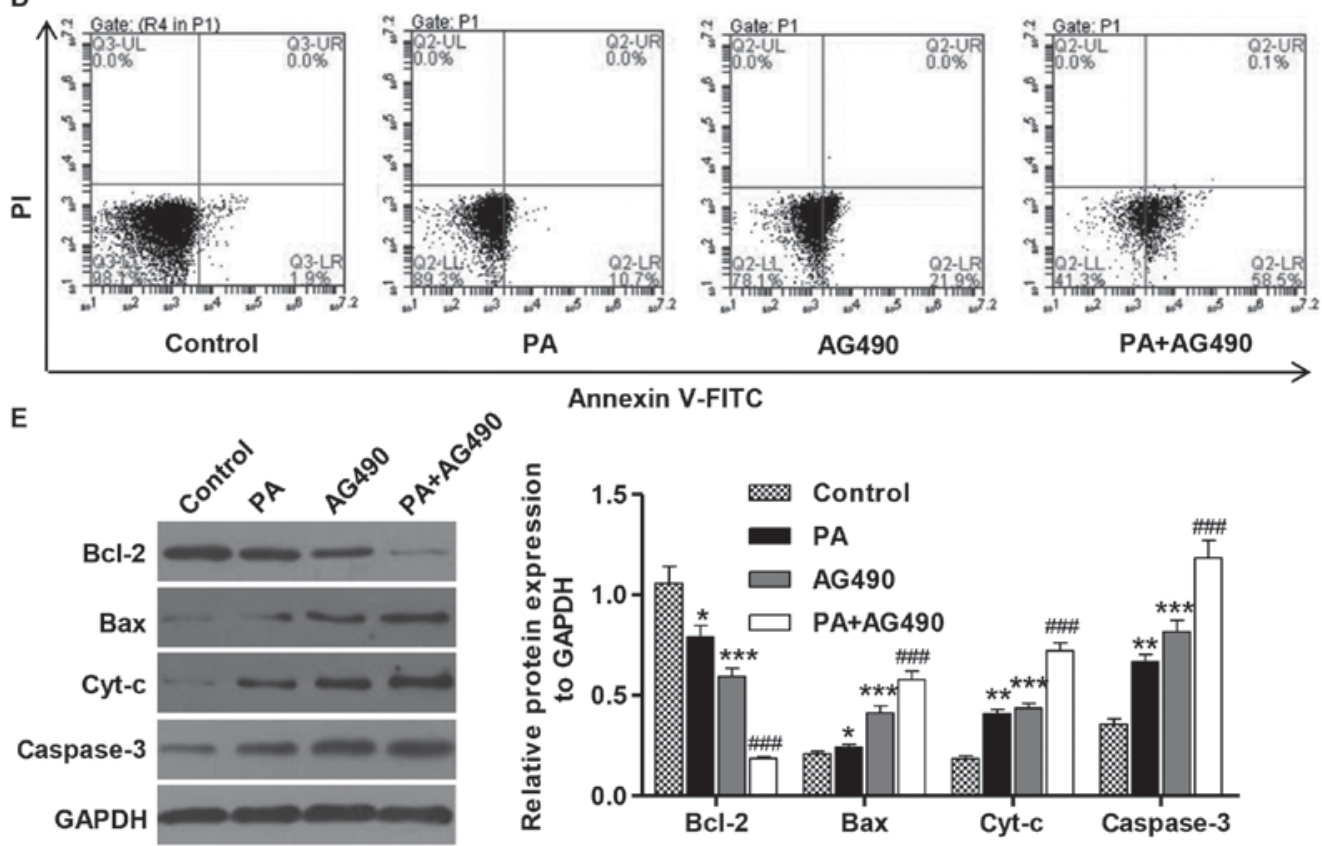

Annexin V-FITC

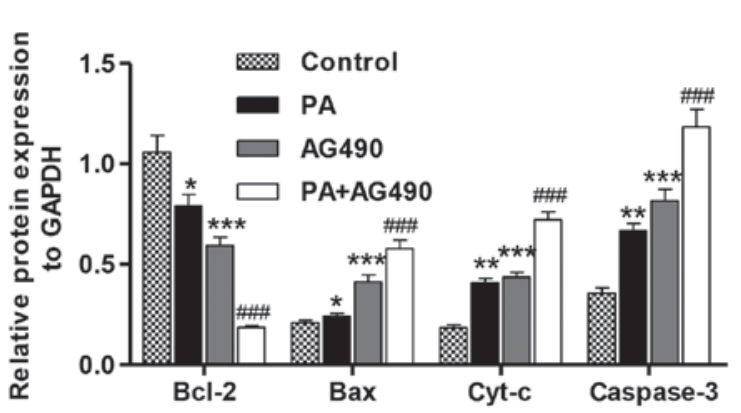

Figure 5. AG490 inhibits cell viability and induces apoptosis of SGC-7901 gastric cancer cells. SGC-7901 cells were treated with PA (80 $\mu$ M) in the absence or presence of AG490 (100 $\mu \mathrm{M})$. (A) The activation of JAK2 and STAT3 was analyzed by western blotting. (B) CCK-8 assay was performed to examine cell viability. (C) Annexin V-FITC/PI staining was used to detect cell apoptosis. (D) Representative cell apoptosis profiles of SGC-7901 cells after PA and/or AG490 treatment. (E) The expression of Bcl-2, Bax, cyt-c and caspase-3 proteins was analyzed by western blotting. These experiments were performed on the same membrane. ${ }^{*} \mathrm{P}<0.05,{ }^{* *} \mathrm{P}<0.01$ and ${ }^{* * *} \mathrm{P}<0.001$ vs. the control group. ${ }^{\#} \mathrm{P}<0.05,{ }^{\# \#} \mathrm{P}<0.01,{ }^{\# \# \#} \mathrm{P}<0.001$ vs. PA or AG490 groups. Bax, BCL2 associated $\mathrm{X}$ protein; Bcl-2, B-cell lymphoma 2; cyt-c, cytochrome c; FITC, fluorescein isothiocyanate; JAK2, Janus kinase 2; PA, pachymicacid; p-, phosphorylated; PI, propidium iodide; STAT3, signal transducer and activator of transcription 3.

with SGC-7901 cells were employed. As presented in Fig. 6A and B, PA treatment at concentrations of 10, 30 and $60 \mathrm{mg} / \mathrm{kg}$ significantly suppressed tumor growth following 28 days in a concentration-dependent manner in comparison with the control group. Moreover, 28 days following treatment with various concentrations of PA, tumor weight was significantly decreased in a concentration-dependent manner in comparison with the control group (Fig. 6C). These results suggest that PA exhibited potent antitumor activity in vivo.

\section{Discussion}

Although chemotherapy is the primary method for the treatment of gastric cancer, the overall survival rate for patients with advanced gastric cancer remains low (5). Natural products have a critical role as an effective source of antitumor agents. Although PA is a promising bioactive molecule, which possesses an anti-carcinogenic activity in numerous types of cancer $(12,17,18)$, the biological activity of PA in gastric cancer is poorly understood. In present study, 
A

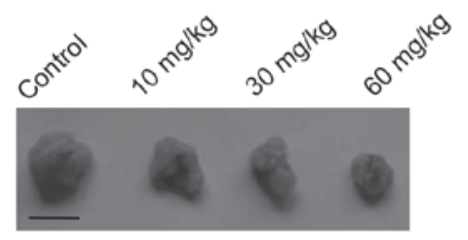

B

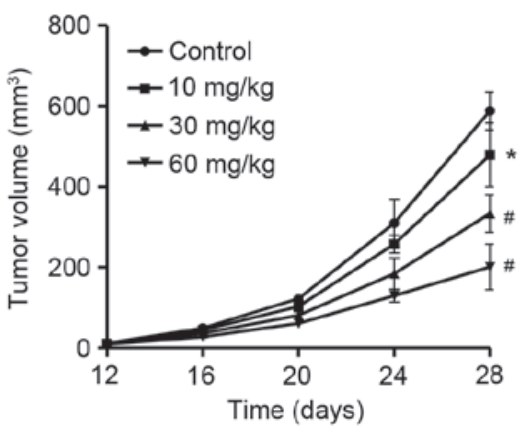

C

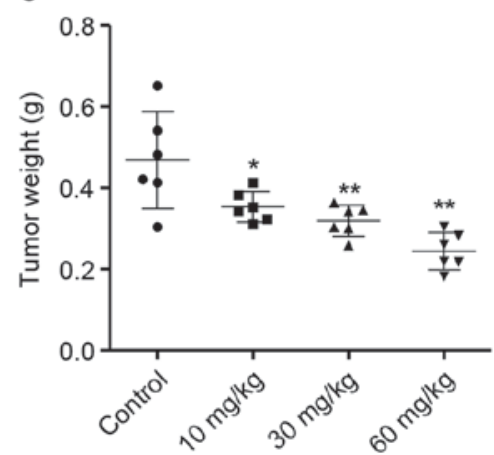

Figure 6. PA inhibits tumor xenograft growth in vivo. (A) Vehicle control and PA (10,30 and $60 \mathrm{mg} / \mathrm{kg})$ were administered for 4 weeks by intraperitoneal injection. (B) Tumor volume and (C) weight of the mice were monitored, respectively. Scale bar, mm. Data in the graphs represent the mean \pm standard deviation $(\mathrm{n}=6) .{ }^{*} \mathrm{P}<0.05,{ }^{* *} \mathrm{P}<0.01,{ }^{*} \mathrm{P}<0.001$ vs. the control group. $\mathrm{PA}$, pachymic acid.

the data indicated that PA was able to inhibit cell viability in a concentration- and time-dependent manner. Previous studies have shown that cell cycle arrest and apoptosis are the mechanisms that induce cell death (19). In the present study, it was observed that treatment with PA was able to induce $\mathrm{G}_{0} / \mathrm{G}_{1}$ phase arrest and apoptosis in SGC-7901 gastric cancer cells. In agreement with our results reported that PA induced cell cycle arrest and apoptosis in lung cancer cells (11) and gallbladder cancer cells (20).

ROS are metabolites with high activity produced during normal cellular metabolism. However, the increase in intracellular ROS in cells may be sufficient to induce apoptosis (21). Furthermore, it has been reported that cell apoptosis is preceded by the following: ROS generation, loss of $\Delta \psi \mathrm{m}$, release of cyt-c and activation of caspase-3 (22). Referring to the results of a previous study and the present study, ROS may be implicated in PA-induced activation of the mitochondrial pathway (11). A decrease in $\Delta \psi \mathrm{m}$ and increased intracellular accumulation of ROS were associated with PA-induced activation of the $\mathrm{Bax} / \mathrm{Bcl}-2$ signaling pathway.

The expression level of Bax is an important indicator of cell apoptosis, which indicated the involvement of the mitochondrial signaling pathway PA-induced apoptosis of SGC-7901 cells. Once activated, Bax is inserted into the mitochondrial membrane, which leads to mitochondrial dysfunction (23). The data of the present study indicated that the expression of Bcl-2 decreased gradually and the expression of Bax in the PA treatment group was increased in a concentration-dependent manner. $\mathrm{Bcl}-2$ regulates apoptosis mainly by preventing the release of cyt-c from the mitochondrion to cytoplasm, activating downstream caspases and ultimately caspase-3 (24). In the present study, caspase-3 activation was coincident with cyt-c release, which suggests that the activation of caspase- 3 is involved inthemitochondrial apoptotic pathway, which was observed in SGC-7901 cells that were treated with PA.

The pathogenic role of JAK/STAT signaling pathway has been documented in a number of cancer types, including breast, ovarian, lung, colorectal and gastric cancer (25-29). In the present study, treatment with PA also resulted in the inactivation of JAK2 and STAT3 in SGC-7901 cells in a dose-dependent manner, suggesting an important role of the JAK2/STAT3 signaling pathway in mediating the inhibitory effects of PA on tumorgrowth. These observations are consistent with previous findings by the present authors where OPB-31121, a novel small molecular inhibitor, was demonstrated to disrupt the JAK2/STAT3 signaling pathway and to exhibit antitumor activity in gastric cancer cells (29).

A xenograft model with SGC-7901 cells in nude mice was used to validate the chemotherapeutic potential of PA on the growth of gastric cancer cells in vivo. To the best of our knowledge, this is the first time that the in vivo anti-proliferative activity of PA has been demonstrated, which further supports the concept that the antitumor effects of PA are strongly dependent on its ability to inhibit tumor growth. This is in line with previous findings that $25 \mathrm{mg} / \mathrm{kg}$ PA was able to significantly suppress the growth of pancreatic cancer tumor in vivo without toxicity, which was also associated with the inhibition of cell proliferation and apoptosis (30).

In conclusion, the present study demonstrated that treatment with PA was able to result in marked anticancer activity in gastric cancer cells by inhibiting cell proliferation as well as inducing cell cycle arrest and apoptosis via the inactivation of the JAK2/STAT3 signaling pathway. Therefore, PA appears to be a potentially attractive bioactive phytochemical for the treatment of gastric cancer.

\section{Acknowledgements}

Not applicable.

\section{Funding}

No funding was received.

\section{Availability of data and materials}

All data generated or analyzed during this study are included in this published article.

\section{Author contributions}

KS and HX conceived and designed the experiments, and wrote the paper. All authors read and approved the final manuscript. 


\section{Ethics approval and consent to participate}

All the experiments were approved by the Animal Ethics Committee at Gongli Hospital of Shanghai Pu Dong New District (Shanghai, China).

\section{Consent for publication}

Not applicable.

\section{Competing interests}

The authors declare that they have no competing interests.

\section{References}

1. Aggarwal A, Guo DL, Hoshida Y, Yuen ST, Chu KM, So S Boussioutas A, Chen X, Bowtell D, Aburatani H, et al: Topological and functional discovery in a gene coexpression meta-network of gastric cancer. Cancer Res 66: 232-241, 2006.

2. Giordano A and Cito L: Advances in gastric cancer prevention. World J Clin Oncol 3: 128-136, 2012.

3. Islami $\mathrm{F}$ and Kamangar F: Helicobacter pylori and esophageal cancer risk: A meta-analysis. Cancer Prev Res (Phila) 1: 329-338, 2008.

4. Kamangar F, Qiao YL, Blaser MJ, Sun XD, Katki H, Fan JH, Perez-Perez GI, Abnet CC, Zhao P, Mark SD, et al: Helicobacter pylori and oesophageal and gastric cancers in a prospective study in China. Br J Cancer 96: 172-176, 2007.

5. Zheng L, Wu C, Xi P, Zhu M, Zhang L, Chen S, Li X, Gu J and Zheng Y: The survival and the long-term trends of patients with gastric cancer in Shanghai, China. BMC Cancer 14: 300, 2014.

6. Ko JK, Leung WC, Ho WK and Chiu P: Herbal diterpenoidsinduce growth arrest and apoptosis in colon cancer cells with increased expression of the nonsteroidal anti-inflammatory drug-activated gene. Eur J Pharmacol 559: 1-13, 2007.

7. Yen CY, Chiu CC, Chang FR, Chen JY, Hwang CC, Hseu YC, Yang HL, Lee AY, Tsai MT, Guo ZL, et al: 4beta-Hydroxywithanolide E from Physalisperuviana (golden berry) inhibits growth of human lung cancer cells through DNA damage, apoptosis and G2/M arrest. BMC Cancer 10: 46, 2010.

8. Shiezadeh F, Mousavi SH, Amiri MS, Iranshahi M, Tayarani-Najaran Z and Karimi G: Cytotoxic and apoptotic potential of Rheum turkestanicumJanisch root extract on human cancer and normal cells. Iran J Pharm Res 12: 811-819, 2013.

9. Rajput S, Kumar BP, Dey KK, Pal I, Parekh A and Mandal M: Molecular targeting of Akt by thymoquinone promotes $\mathrm{G} 1$ arrest through translation inhibition of cyclin D1 and induces apoptosis in breast cancer cells. Life Sci 93: 783-790, 2013.

10. Cheng S, Eliaz I, Lin J, Thyagarajan-Sahu A and Sliva D: Triterpenes from Poria cocos suppress growth and invasiveness of pancreatic cancer cells through the downregulation of MMP-7. Int J Oncol 42: 1869-1874, 2013.

11. Ma J, Liu J, Lu C and Cai D: Pachymic acid induces apoptosis via activating ROS-dependent JNK and ER stress pathways in lung cancer cells. Cancer Cell Int 15: 78, 2015.

12. Gapter L, Wang Z, Glinski J and Ng KY: Induction of apoptosis in prostate cancer cells by pachymic acid from Poriacocos. Biochem Biophys Res Commun 332: 1153-1161, 2005.

13. Huang YC, Chang WL, Huang SF, Lin CY, Lin HC and Chang TC: Pachymic acid stimulates glucose uptake through enhanced GLUT4 expression and translocation. Eur J Pharmacol 648: 39-49, 2010.

14. Tomayko MM and Reynolds CP: Determination of subcutaneous tumor size in athymic (nude) mice. Cancer Chemother Pharmacol 24: 148-154, 1989.
15. Ly JD, Grubb D and Lawen A: The mitochondrial membrane potential (deltapsi(m)) in apoptosis; an update. Apoptosis 8: $115-128,2003$.

16. Qu K, Shen NY, Xu XS, Su HB, Wei JC, Tai MH, Meng FD, Zhou L, Zhang YL and Liu C: Emodin induces human T cell apoptosis in vitro by ROS-mediated endoplasmic reticulum stress and mitochondrial dysfunction. Acta Pharmacol Sin 34: 1217-1228, 2013.

17. Hong R, Shen MH, Xie XH and Ruan SM: Inhibition of breast cancer metastasis via PITPNM3 by pachymic acid. Asian Pac J Cancer Prev 13: 1877-1880, 2012.

18. Ling H, Zhang Y, Ng KY and Chew EH: Pachymic acid impairs breast cancer cell invasion by suppressing nuclear factor- $\kappa \mathrm{B}$-dependent matrix metalloproteinase-9 expression. Breast Cancer Res Treat 126: 609-620, 2011.

19. King K and Cidlowski J: Cell cycle regulation and apoptosis. Ann Rev Physiol 60: 601-617, 1998.

20. Chen Y, Lian P, Liu Y and Xu K: Pachymic acid inhibits tumorigenesis in gallbladder carcinoma cells. Int J Clin Exp Med 8: $17781-17788,2015$.

21. Curtin JF, Donovan M and Cotter TG: Regulation and measurement of oxidative stress in apoptosis. J Immunol Methods 265 49-72, 2002.

22. Herrera B, Fernández M, Alvarez AM, Roncero C, Benito M, Gil J and Fabregat I: Activation of caspases occurs downstream from radical oxygen species production, Bcl-xL down-regulation, and early cytochrome $\mathrm{C}$ release in apoptosis induced by transforming growth factor beta in rat fetal hepatocytes. Hepatology 34: 548-556, 2001

23. Green DR and Chipuk JE: Apoptosis: Stabbed in the BAX. Nature 455: 1047-1049, 2008.

24. Zhu X, Zhang K, Wang Q, Chen S, Gou Y, Cui Y and Li Q: Cisplatin-mediated c-myc overexpression and cytochrome c (cyt c) release result in the up-regulation of the death receptors DR4 and DR5 and the activation of caspase 3 and caspase 9, likely responsible for the TRAIL-sensitizing effect of cisplatin. Med Oncol 32: 133, 2015.

25. Marotta LL, Almendro V, Marusyk A, Shipitsin M, Schemme J, Walker SR, Bloushtain-Qimron N, Kim JJ, Choudhury SA, Maruyama R, et al: The JAK2/STAT3 signaling pathway is required for growth of CD44(+)CD24(-) stem cell-like breast cancer cells in human tumors. J Clin Invest 121: 2723-2735, 2011.

26. Colomiere M, Ward AC, Riley C, Trenerry MK, Cameron-Smith D, Findlay J, Ackland L and Ahmed N: Cross talk of signals between EGFR and IL-6R through JAK2/STAT3 mediate epithelial-mesenchymal transition in ovarian carcinomas. Br J Cancer 100: 134-144, 2009.

27. Zhao M, Gao FH, Wang JY, Liu F, Yuan HH, Zhang WY and Jiang B: JAK2/STAT3 signaling pathway activation mediates tumor angiogenesis by upregulation of VEGF and bFGF in non-small-cell lung cancer. Lung Cancer 73: 366-374, 2011.

28. Xiong H, Du W, Zhang YJ, Hong J, Su WY, Tang JT, Wang YC, Lu R and Fang JY: Trichostatin A, a histone deacetylase inhibitor, suppresses JAK2/STAT3 signaling via inducing the promoter-associated histone acetylation of SOCS1 and SOCS3 in human colorectal cancer cells. Mol Carcinog 51: 174-184, 2012.

29. Kim MJ, Nam HJ, Kim HP, Han SW, Im SA, Kim TY, Oh DY and Bang YJ: OPB-31121, a novel small molecular inhibitor, disrupts the JAK2/STAT3 pathway and exhibits an antitumor activity in gastric cancer cells. Cancer Lett 335: 145-152, 2013.

30. Cheng S, Swanson K, Eliaz I, McClintick JN, Sandusky GE and Sliva D: Pachymic acid inhibits growth and induces apoptosis of pancreatic cancer in vitro and in vivo by targeting ER stress. PloS One 10: e0122270, 2015. 